\title{
Risk Factors for Hemorrhagic Complications following Pipeline Embolization Device Treatment of Intracranial Aneurysms: Results from the International Retrospective Study of the Pipeline Embolization Device
}

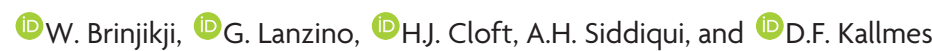

\begin{abstract}
BACKGROUND AND PURPOSE: Spontaneous intraparenchymal hemorrhage is a dreaded complication of unknown etiology following flow-diversion treatment. Using the International Retrospective Study of the Pipeline Embolization Device registry, we studied demographic, aneurysm, and procedural characteristics associated with intraparenchymal hemorrhage following Pipeline Embolization Device treatment.
\end{abstract}

\begin{abstract}
MATERIALS AND METHODS: We identified patients in the International Retrospective Study of the Pipeline Embolization Device registry with intraparenchymal hemorrhage unrelated to index aneurysm rupture post-Pipeline Embolization Device treatment. The rate of intraparenchymal hemorrhage was determined by baseline demographics, comorbidities, aneurysm characteristics, and procedural characteristics (including anticoagulation use, platelet testing, number of devices used, sheaths, catheters, and guidewires). Categoric variables were compared with $\chi^{2}$ testing, and continuous variables were compared with the Student $t$ test.

RESULTS: Of 793 patients with 906 aneurysms, 20 (2.5\%) had intraparenchymal hemorrhage. Fifteen intraparenchymal hemorrhages (75.0\%) occurred within 30 days of treatment (median, 5 days; range, $0-150$ days). Nine patients with intraparenchymal hemorrhage (45.0\%) died, 10 (50.0\%) had major neurologic morbidity, and 1 had minor neurologic morbidity (5.0\%). Intraparenchymal hemorrhage was ipsilateral to the Pipeline Embolization Device in 16 patients (80\%) and contralateral in 3 patients (15.0\%). Variables associated with higher odds of intraparenchymal hemorrhage included treatment of ruptured aneurysms (OR, 4.44; 95\% Cl, 1.65-11.94; $P=.005)$ and the use of $\geq 3$ Pipeline Embolization Devices (OR, 4.10; $95 \% \mathrm{Cl}, 1.34-12.58 ; P=.04)$. The Shuttle sheath was not associated with intraparenchymal hemorrhage (OR, $0.97 ; 95 \% \mathrm{Cl}, 0.38-2.45 ; P=.95)$.

CONCLUSIONS: Spontaneous intraparenchymal hemorrhage following Pipeline Embolization Device treatment is a rare-but-devastating complication, with nearly all patients having morbidity or mortality. Variables associated with intraparenchymal hemorrhage included the use of multiple Pipeline Embolization Devices and treatment of ruptured aneurysms. The Shuttle, a device that was previously thought to be associated with intraparenchymal hemorrhage, was not associated with it.
\end{abstract}

ABBREVIATIONS: IntrePED = International Retrospective Study of the Pipeline Embolization Device; IPH = intraparenchymal hemorrhage; PED = Pipeline Embolization Device

$\mathbf{T}$ he Pipeline Embolization Device (PED; Covidien, Irvine, California) is increasingly used in the treatment of intracranial aneurysms. ${ }^{1-4}$ The bare metal construct of the PED serves as a scaffold for neointimal proliferation, thereby excluding the aneurysm sac from the parent artery. ${ }^{5,6}$ A number of previous studies

Received February 9, 2015; accepted after revision May 10.

From the Departments of Radiology (W.B., G.L., H.J.C., D.F.K.) and Neurosurgery (G.L., H.J.C., D.F.K.), Mayo Clinic, Rochester, Minnesota; and Department of Neurosurgery (A.H.S.), State University of New York, Buffalo, New York.

Please address correspondence to Waleed Brinjikji, MD, Mayo Clinic, 200 First St SW, OL1-112 SMH, Rochester, MN 55905; e-mail: brinjikji.waleed@mayo.edu; @Wbrinjikji

http://dx.doi.org/10.3174/ajnr.A4443 have demonstrated that the PED is associated with high rates of aneurysm occlusion with relatively low complication rates. ${ }^{1,3}$

Spontaneous intraparenchymal hemorrhage (IPH) is one of the most dreaded complications of aneurysm treatment with flow diverters. ${ }^{7-13}$ Although rarely reported after stent-assisted coiling of aneurysms, systematic reviews of flow-diverter treatment suggest that this complication occurs in $2 \%-4 \%$ of patients. Little is known regarding the exact etiology or risk factors of post-flowdiverter IPH. ${ }^{7-13}$ A number of theories have been proposed, including the use of dual antiplatelet therapy, activation of platelets despite antiplatelet therapy by shearing over the metal surface area and subsequent hemorrhagic transformation of embolic platelet plug-mediated ischemic stroke, hemodynamic perturbations (hypo- or hyperperfusion states) during and immediately 
after flow-diverter treatment, and embolization of polyvinylpyrrolidone, a compound found in a number of catheters including the Shuttle guide sheath (Cook, Bloomington, Indiana). ${ }^{10}$ Using the International Retrospective Study of the Pipeline Embolization Device (IntrePED) registry, we compared the clinical and procedural characteristics of patients who had postoperative IPH and those who did not, to determine which clinical and procedural characteristics were associated with IPH.

\section{MATERIALS AND METHODS \\ Study Design and Participants}

This study is a subanalysis of the IntrePED study, which has been previously published. ${ }^{14}$ Details regarding ethics committee and institutional review board approval and inclusion and exclusion criteria are provided in the original article. ${ }^{14}$ Several additional subgroup analyses separate from this study are currently underway by using data from the IntrePED registry. This study will be the only subgroup analysis performed examining variables associated with IPH in the IntrePED registry. We retrospectively evaluated all patients with intracranial aneurysms treated with the Pipeline Embolization Device in the IntrePED registry. Seven hundred ninety-three patients treated for 906 aneurysms were enrolled.

\section{Procedures}

Because this was a retrospective registry, procedural details and patient management varied across centers. All centers reported baseline characteristics of patients and aneurysms, procedural information, and follow-up information from clinic visits or telephone calls by using a common study protocol form. Site investigators identified patients who had IPH by using the study protocol form. All complications including IPH were reviewed in detail by an Adverse Events Review Committee, comprising 3 members of the Steering Committee, including the overall study Principal Investigator. The committee determined whether the IPH was major or minor. A "major" adverse event was defined as an ongoing clinical deficit at 7 days following the event. All major adverse events were included in the neurologic morbidity and mortality rates. Timing of all adverse events was in relation to the time of the PED placement.

\section{Baseline Characteristics and Outcomes}

For each patient, the following characteristics were collected as part of this study: age, sex, hypertension, control of hypertension, smoking status, aneurysm location, aneurysm rupture status, aneurysm type, aneurysm size, use of antiplatelet medications before the procedure, use of platelet aggregation studies, heparin administration and reversal, number of PEDs used, type of sheath used, type of guide catheter used, type of microcatheter used, type of guidewire used, balloons used, and type of closure device used. The incidence of IPH was calculated for each of the above-mentioned variables.

In addition, for patients with any cerebrovascular hemorrhagic complication, we obtained the following information: whether the hemorrhage was ipsilateral or contralateral to the device; timing after surgery; final clinical outcome (minor morbidity, major morbidity, death); and a clinical report of a preced- ing embolic event and other procedural complications, including but not limited to vessel perforation. "Minor morbidity" was defined as a clinical deficit that persisted $<7$ days, and "major morbidity" was defined as a clinical deficit that persisted $\geq 7$ days.

\section{Statistical Analysis}

Statistical analyses were performed by using SAS, Version 9.2 or higher (SAS Institute, Cary, North Carolina). Descriptive statistics will be used to present the data and to summarize the results. Discrete variables will be presented by using frequency distributions and cross-tabulations. Continuous variables will be summarized by presenting the number of observations and mean, SD, median, minimum, and maximum values. For categoric variables, differences between the randomized arms were tested by using appropriate contingency table analyses (Exact or $\chi^{2}$ approximations). For continuous variables, the differences were tested by using an unpaired Student $t$ test or a nonparametric test, depending on variable distribution. Odds ratios and 95\% confidence intervals were obtained by using the univariate logistic regression. All statistical analyses were performed on a per-patient basis.

\section{Role of the Funding Source}

An academic Principal Investigator and an academic Steering Committee supervised the trial design and operations. The Principal Investigator and Steering Committee were independent of the funding source. The Steering Committee interpreted the results, and the Principal Investigator wrote the report. The study sponsor was responsible for site management, data management, statistical analysis, and safety reporting. The corresponding author had full access to all study data and had final responsibility for the decision to submit for publication.

\section{RESULTS}

\section{Patient and Aneurysm Characteristics and IPH}

A summary of the baseline characteristics of all patients included in the IntrePED registry is provided elsewhere. ${ }^{14}$ Twenty (2.5\%) patients with 21 treated aneurysms had IPH, while 773 patients $(97.5 \%)$ did not. There was no difference in the mean age of patients with and without IPH $(61.4 \pm 13.4$ years versus $56.8 \pm 14.2$ years, $P=.16)$. Smoking rates (OR, $1.41 ; 95 \% \mathrm{CI}, 0.40-4.92 ; P=$ .59) were not associated with IPH. There was a trend toward higher odds of IPH in the hypertension group (OR, 2.45; 95\% CI, $0.96-6.23 ; P=.06)$. These data are summarized in Table 1 .

No aneurysm locations were associated with higher or lower odds of IPH. There was a similar rate of IPH in anterior circulation versus posterior circulation aneurysms (OR, 1.14; 95\% CI, $0.26-5.00 ; P=.86)$. Treatment of ruptured aneurysms was associated with higher odds of IPH (OR, 4.44; 95\% CI, 1.65-11.95; $P=.005)$. There was no difference in IPH rates by aneurysm type or aneurysm size. These data are summarized in Table 1.

\section{Procedure Characteristics}

Use of $\geq 3$ PEDs (OR, 4.10; 95\% CI, 1.34-12.58; $P=.04$ ) was associated with higher odds of IPH. Use of the Shuttle was not associated with higher odds of IPH (OR, 0.95; 95\% CI, 0.38-2.45; $P=.95$ ). Pretreatment antiplatelet therapy (OR, 0.93; 95\% CI, 
Table 1: Demographic and aneurysm characteristics

\begin{tabular}{|c|c|c|c|}
\hline Characteristics & IPH/Subtotal & OR & $P$ Value \\
\hline \multicolumn{4}{|l|}{ Sex } \\
\hline Male & $2.5 \%(4 / 161)$ & Ref & \\
\hline Female & $2.5 \%(16 / 632)$ & $1.02(0.34-3.09)$ & .97 \\
\hline \multicolumn{4}{|l|}{ Hypertension } \\
\hline Yes & $5.2 \%(13 / 249)$ & $2.45(0.96-6.23)$ & .06 \\
\hline No & $2.2 \%(7 / 318)$ & Ref & \\
\hline \multicolumn{4}{|l|}{ Controlled hypertension } \\
\hline Yes & $5.8 \%(12 / 206)$ & $0.58(0.02-15.92)$ & .75 \\
\hline No & $0.0 \%(0 / 4)$ & Ref & \\
\hline \multicolumn{4}{|l|}{ Current smoker } \\
\hline Yes & $3.2 \%(3 / 94)$ & $1.32(0.38-4.60)$ & .66 \\
\hline No & $2.4 \%(17 / 699)$ & Ref & \\
\hline \multicolumn{4}{|l|}{ Aneurysm location } \\
\hline Posterior circulation & $2.2 \%(2 / 89)$ & Ref & \\
\hline Anterior circulation & $2.6 \%(18 / 704)$ & $1.14(0.26-5.00)$ & .86 \\
\hline \multicolumn{4}{|c|}{ Aneurysm location by vessel } \\
\hline Internal carotid artery & $2.4 \%(14 / 590)$ & Ref & \\
\hline PcomA & $3.8 \%(2 / 53)$ & $1.61(0.36-7.30)$ & .78 \\
\hline ACA & $25.0 \%(2 / 8)$ & $13.71(2.54-74.02)$ & .01 \\
\hline Basilar artery & $2.3 \%(1 / 43)$ & $0.98(0.13-7.63)$ & .43 \\
\hline Vertebral artery & $3.0 \%(1 / 33)$ & $1.29(0.16-10.09)$ & .63 \\
\hline \multicolumn{4}{|l|}{ Rupture status } \\
\hline Unruptured & $1.9 \%(14 / 719)$ & Ref & \\
\hline Ruptured & $8.1 \%(6 / 74)$ & $4.44(1.65-11.94)$ & .00 \\
\hline \multicolumn{4}{|l|}{ Aneurysm type } \\
\hline Saccular & $2.0 \%(12 / 600)$ & Ref & \\
\hline Fusiform & $3.9 \%(4 / 102)$ & $1.92(0.42-8.82)$ & .91 \\
\hline Dissecting & $3.8 \%(2 / 53)$ & $2.00(0.63-6.33)$ & .82 \\
\hline Other & $5.3 \%(2 / 38)$ & $2.72(0.59-12.63)$ & .48 \\
\hline \multicolumn{4}{|l|}{ Aneurysm size } \\
\hline$<10 \mathrm{~mm}$ & $1.6 \%(6 / 387)$ & Ref & \\
\hline $10-24.9 \mathrm{~mm}$ & $3.3 \%(11 / 338)$ & $2.14(0.78-5.84)$ & .70 \\
\hline$\geq 25 \mathrm{~mm}$ & $4.8 \%(3 / 63)$ & $3.18(0.77-13.04)$ & .23 \\
\hline
\end{tabular}

Note:-PcomA indicates posterior communicating artery; ACA, anterior cerebral artery; Ref, reference.

with associated SAH resulting from spontaneous rupture of a treated giant cavernous carotid aneurysm.

\section{DISCUSSION}

Our current large, multicenter study of flow-diversion therapy confirms that approximately $2 \%$ of patients will have ipsilateral IPH. All patients who experienced IPH in our study had either major morbidity or mortality. Most IPH cases occurred within the first week of the procedure, and all cases occurred within 6 months of the procedure. In our series, treatment variables associated with IPH included treatment of ruptured aneurysms and the use of $\geq 3$ PEDs. The Shuttle, a device that was previously postulated to be associated with IPH, was not associated with IPH in our study. ${ }^{10,12}$ These findings suggest that the etiology of IPH following PED treatment is multifactorial, due to a constellation of risk factors, including aneurysm rupture status and the use of multiple PEDs.

The exact mechanism of IPH following PED treatment is uncertain, but a number of different theories have been proposed. One histopathologic study of 3 patients who died after PED-associated intracranial hemorrhage demon-

0.27-3.23), preprocedual platelet aggregation studies (OR, 0.95; 95\% CI, 0.36-2.49; $P=.91$ ), and heparin administration (OR, $1.14 ; 95 \% \mathrm{CI}, 0.26-5.00 ; P=.92)$ were not associated with IPH. No microcatheters, sheaths, or guidewires were associated with IPH. The use of closure devices was not associated with IPH. These data are summarized in Table 2.

\section{Timing and Clinical Outcomes of IPH}

Of the 20 patients who had IPH, 11 (55.0\%) had it within 1 week of the procedure. Four patients (20.0\%) had IPH between 1 week and 1 month of the procedure, 1 patient had IPH between 1 and 3 months of the procedure (5.0\%), and 3 patients had IPH between 3 and 6 months of the procedure (15.0\%). No patients had IPH after 6 months following treatment. The median time of onset for IPH was 5 days, the mode was 1 day as 6 patients had IPH 1 day following treatment. In 1 patient, the timing of the IPH was uncertain. Among patients with IPH, 9 (45.0\%) died, 10 (50.0\%) had major neurologic morbidity, and 1 patient (5.0\%) had minor neurologic morbidity. The location of the IPH was ipsilateral to the device in 16 patients $(80.0 \%)$ and contralateral to the device in 3 patients (15.0\%). In 1 patient, the location of the hemorrhage was unknown. Four patients with IPH (20.0\%) had a clinical ischemic event (transient ischemic attack or stroke) before the IPH. One patient had IPH the day after the procedure following perforation of a vessel with a guidewire, and 1 patient had IPH strated that in each case, there was evidence of a foreign material (polyvinylpyrrolidone) in the distal vasculature of the hemorrhagic lesion. ${ }^{10}$ Polyvinylpyrrolidone is a substance that is commonly used as a coating material for a number of interventional devices, including the Shuttle guide sheath. In that study, the authors demonstrated that macroscopic bits of polyvinylpyrrolidone could be released from this device with minimal manipulation. ${ }^{10}$ In addition, other studies from the interventional cardiology literature have demonstrated that friction during placement and manipulation of the Shuttle sheath results in deposition of hydrophilic embolic materials causing substantial foreign-body reactions. ${ }^{15-17}$ Polyvinylpyrrolidone emboli have been shown to result in angiothrombosis and granulomatous angiitis, with resultant vascular injuries. ${ }^{18}$ However, Hu et al ${ }^{10}$ did not find any evidence of such granulomatous reaction in association with these polyvinylpyrrolidone emboli following PED treatment. In our current study, we found no association between the Shuttle and IPH following flow-diversion therapy. Given the large size of our study compared with prior studies implicating the Shuttle as causing IPH, our data call into question the association.

The use of dual antiplatelet agents has also been proposed as a potential etiology of IPH. In general, patients treated with flow diverters such as the PED are treated with at least 3 months of dual antiplatelet therapy. A number of studies have demonstrated that most IPHs following PED placement occur within 1 month and 
Table 2: Procedure and device characteristics

\begin{tabular}{|c|c|c|c|}
\hline Characteristics & IPH/Subtotal ${ }^{\mathrm{a}}$ & OR & $P$ Value \\
\hline \multicolumn{4}{|l|}{ Preprocedural antiplatelet use } \\
\hline Yes & $2.5 \%(17 / 681)$ & $0.93(0.27-3.23)$ & .91 \\
\hline No & $2.7 \%(3 / 112)$ & Ref & \\
\hline \multicolumn{4}{|c|}{ Preprocedural platelet aggregation studies } \\
\hline Yes & $2.5 \%(14 / 564)$ & $0.95(0.36-2.49)$ & .91 \\
\hline No & $2.6 \%(6 / 229)$ & Ref & \\
\hline \multicolumn{4}{|l|}{ Heparin administration } \\
\hline Yes & $2.6 \%(18 / 704)$ & $1.14(0.26-5.00)$ & .86 \\
\hline No & $2.2 \%(2 / 89)$ & Ref & \\
\hline \multicolumn{4}{|l|}{ Reversal of heparin } \\
\hline Yes & $5.6 \%(1 / 18)$ & $2.33(0.29-18.49)$ & .43 \\
\hline No & $2.5 \%(17 / 689)$ & Ref & \\
\hline \multicolumn{4}{|l|}{ No. of PEDs used } \\
\hline 1 & $1.7 \%(9 / 533)$ & Ref & \\
\hline 2 & $3.3 \%(6 / 183)$ & $1.97(0.69-5.62)$ & .96 \\
\hline $3+$ & $6.6 \%(5 / 76)$ & $4.10(1.34-12.58)$ & .04 \\
\hline \multicolumn{4}{|l|}{ How multiple PEDs were used } \\
\hline Overlapping & $1.4 \%(2 / 140)$ & Ref & \\
\hline Multiple layers & $7.5 \%(3 / 40)$ & $5.59(0.90-34.72)$ & .96 \\
\hline Additional length & $7.9 \%(6 / 76)$ & $5.91(1.16-30.06)^{\prime}$ & .96 \\
\hline Multiple layers and overlapping & $0.0 \%(0 / 2)$ & NA & \\
\hline \multicolumn{4}{|l|}{ Sheaths used } \\
\hline \multicolumn{4}{|l|}{ Medical Arrow-Flex ${ }^{b}$} \\
\hline Yes & $0.0 \%(0 / 35)$ & NA & \\
\hline No & $3.5 \%(19 / 546)$ & & \\
\hline \multicolumn{4}{|l|}{ Medical Shuttle Select } \\
\hline Yes & $3.2 \%(8 / 249)$ & $0.97(0.38-2.45)$ & .95 \\
\hline No & $3.3 \%(11 / 332)$ & Ref & \\
\hline \multicolumn{4}{|l|}{ Pinnacle Destination ${ }^{c}$} \\
\hline Yes & $5.9 \%(2 / 34)$ & $1.95(0.43-8.80)$ & .39 \\
\hline No & $3.1 \%(17 / 547)$ & Ref & \\
\hline \multicolumn{4}{|l|}{ Microcatheter used } \\
\hline \multicolumn{4}{|l|}{ Marksman ${ }^{d}$} \\
\hline Yes & $3.2 \%(18 / 557)$ & $0.77(0.10-6.00)$ & .80 \\
\hline No & $4.2 \%(1 / 24)$ & Ref & \\
\hline
\end{tabular}

${ }^{a}$ The number of IPHs does not add up to 20 in all subanalyses because these data were missing in some patients.

b Teleflex, Limerick, Pennsylvania.

'Terumo, Tokyo, Japan.

${ }^{\mathrm{d}}$ Covidien, Irvine, California.

events occurring beyond 6 months are exceedingly rare..$^{8,10,11}$ The fact that the timing of these events and the duration of dual antiplatelet therapy coincide cannot be dismissed. In our study, it would be impossible to find a statistical correlation between the use of antiplatelet agents and hemorrhage as by design, all patients were to be maintained on dual antiplatelet regimens. Studies examining the association between preprocedural $\mathrm{P} 2 \mathrm{Y} 12$ reaction units and the risk of hemorrhagic complications have demonstrated that $\mathrm{P} 2 \mathrm{Y} 12$ reaction unit values of $<60$ portend a higher risk of hemorrhage. ${ }^{11,19}$ We did not study the association between P2Y12 reaction unit values and hemorrhagic complications. However, we found no association between the use of platelet testing and the risk of hemorrhagic complications. To date, no studies have demonstrated a decreased risk of hemorrhagic complications among patients receiving a titration of dual antiplatelet therapy in response to results of platelet testing, to our knowledge.

Intraparenchymal hemorrhages have been previously reported following standard stent-assisted coiling of intracranial aneurysms; however, these events tend to be exceedingly rare. ${ }^{20-22}$ Typically, intracranial stent placement requires dual antiplatelet therapy for at least 3 months, similar to PED use, so the increased number of reported IPHs among PED patients relative to stent- coil patients suggests an innate increase in the incidence with PEDs. One may speculate that the increased metal surface area to which the platelets are exposed may result in activation through increased shear, despite antiplatelet therapy. This may cause activated platelet plugs embolizing distally with secondary hemorrhagic transformation of resulting ischemic infarcts. This hypothesis is given credence through our findings of a 4-fold increase in IPH following multiple PEDs, which would nominally reflect a much greater metal surface shear area exposed to platelets. To date, no studies have conclusively linked silent infarcts to IPH, to our knowledge. In fact, 1 small study of 4 patients with post-flow-diverter-therapy IPH and imaging in the immediate postoperative period before the IPH found no cases of ischemic lesions preceding the development of IPH. ${ }^{23}$

The exact cause behind the significantly increased incidence following treatment of ruptured aneurysms as noted in our study is not clear. It is possible that the increased acute-phase reactant environment could facilitate platelet activation and result in subsequent embolic and thereby hemorrhagic events. While most of the ruptured aneurysms treated in this study were not treated in the acute phase of subarachnoid hemorrhage, studies suggest that acute-phase proteins can remain elevated for several months following subarachnoid hemorrhage. ${ }^{24}$

Another hypothesis that has been suggested regarding the etiology of IPH is one of hyperperfusion following PED placement. This is thought to be due to a sudden loss of a large capacitance chamber in the form of a giant aneurysm. Chiu and Wenderoth ${ }^{25}$ postulated that cerebral hyperperfusion syndrome can occur following the placement of a flow-diverting device across an aneurysm neck. In their case report, the authors suggested that by diverting blood flow from the aneurysm sac into the parent vessel and reducing aneurysm expansion during systole, flow-diverting stents effectively increase the degree of perfusion to the distal arterial territory and can result in cerebral hyperperfusion syndrome due to the Windkessel effect. ${ }^{7,25}$ Similar hemodynamic perturbations have been seen following surgical clipping. ${ }^{26}$ However, our data found no correlation with aneurysm size, which would argue against this concept.

Our study demonstrated a strong association between the use of multiple PEDs and hemorrhagic events. The use of multiple PEDs has been shown to be associated with poor neurologic outcome related to thromboembolic and hemorrhagic complications in 1 previous series of 74 patients. ${ }^{27}$ However, to our knowledge, 
no previous study has to date demonstrated a strong statistical correlation between the use of multiple PEDs and IPH. The association between the use of multiple PEDs and hemorrhagic complications is likely due to multiple factors including prolonged procedural time, increased platelet activation, and possible hemodynamic alterations from the placement of multiple stents. ${ }^{19,25}$

\section{Limitations}

Our study has limitations. First, because the number of IPH events was low, we are limited in our power to detect associations between IPH and the above-mentioned variables. Our study protocol did not require regular postoperative imaging with CT or MR imaging. Thus, we cannot determine whether these areas of hemorrhage are due to hemorrhagic transformation of silent infarctions. Another limitation is that for patients receiving platelet testing, we do not have information regarding platelet responsiveness before the hemorrhagic event or whether and how antiplatelet prescriptions changed in response to these tests.

Last, we do not have any consistent data regarding how these hemorrhages were managed. A recent study by Tomas et $\mathrm{al}^{23}$ demonstrated that surgical evacuation of IPHs following flowdiverter treatment resulted in favorable clinical outcome on follow-up. These procedures were safe and effective in all 4 cases in the Tomas et al study, despite the use of dual antiplatelet therapy as all patients had platelet transfusion immediately before the surgical procedure. Single antiplatelet therapy with aspirin in the immediate postoperative period was safe and effective in all 4 cases as no patients had rehemorrhage or in-stent thrombosis or stroke.

\section{CONCLUSIONS}

Spontaneous IPH following endovascular treatment of intracranial aneurysms with the PED is a rare-but-devastating complication with $100 \%$ of patients having major morbidity or mortality. The exact cause of this complication is not well-established and is likely multifactorial. Variables associated with IPH include use of multiple PEDs and treatment of ruptured aneurysms. All IPHs occurred within 6 months of the procedures, suggesting that the use of antiplatelet therapy is a potential risk factor. The Shuttle, a device that was previously thought to be associated with IPH, was not associated with it in this study. Future efforts for reducing the risk of hemorrhagic complications following PED placement should focus on limiting the number of PEDs used, when possible.

Disclosures: Giuseppe Lanzino-UNRELATED: Consultancy: Covidien.* Adnan Siddiqui-UNRELATED: Board Membership: Codman \& Shurtleff, Covidien, Intersocietal Commission for the Accreditation of Vascular Laboratories, Medina Medical; Consultancy: Codman \& Shurtleff, Covidien, GuidePoint Global, Penumbra, Stryker, Pulsar Vascular, MicroVention, Lazarus Effect, Blockade Medical, Reverse Medical; Grants/Grants Pending: National Institutes of Health, ${ }^{*}$ University at Buffalo, ${ }^{*}$ Comments: The National Institutes of Health (coinvestigator: National Institute of Neurological Disorders and Stroke, IR01NS064592-01A1, Hemodynamic Induction of Pathologic Remodeling Leading to Intracranial Aneurysms); University at Buffalo (Research Development Award); the National Institutes of Health (coinvestigator: $\mathrm{Na-}$ tional Institute of Biomedical Imaging and Bioengineering, 5 R01 EB002873-07, Micro-Radiographic Image for Neurovascular Interventions); Payment for Lectures (including service on Speakers Bureaus): Codman \& Shurtleff; Stock/Stock Options: Hotspur, Intratech Medical, STIMSOX, Valor Medical, Blockade Medical, Lazarus Effect, Pulsar Vascular, Medina Medical; Other: national steering committees for various trials; honoraria from Abbott Vascular and Penumbra, Comments: Penumbra, 3D
Separator Trial; Covidien, Solitaire With the Intention For Thrombectomy as PRIMary Endovascular Treatment Trial; MicroVention, Flow Re-Direction Endoluminal Device Trial. David F. Kallmes—RELATED: Grant: ev3/Covidien, ${ }^{*}$ Comments: funding for a clinical trial; Consulting Fee or Honorarium: ev3/Covidien, ${ }^{*}$ Comments: funding for the Steering Committee; Fees for Participation in Review Activities such as Data Monitoring Boards, Statistical Analysis, Endpoint Committees, and the Like: ev3/ Covidien, ${ }^{*}$ Comments: funding for Adverse Event Review Committee; UNRELATED: Board Membership: GE Healthcare (Cost-Effectiveness Board); Grants/Grants Pending: MicroVention, ${ }^{*}$ Codman, ${ }^{*}$ SurModics, ${ }^{*}$ NeuroSigma, ${ }^{*}$ Sequent Medical,* ev3/Covidien, Comments: support for preclinical and clinical trials; Royalties: University of Virginia Patent Foundation (Spine Fusion). *Money paid to the institution.

\section{REFERENCES}

1. Arrese I, Sarabia R, Pintado R, et al. Flow-diverter devices for intracranial aneurysms: systematic review and meta-analysis. Neurosurgery 2013;73:193-99; discussion 199-200 CrossRef Medline

2. Briganti F, Napoli M, Tortora F, et al. Italian multicenter experience with flow-diverter devices for intracranial unruptured aneurysm treatment with periprocedural complications: a retrospective data analysis. Neuroradiology 2012;54:1145-52 CrossRef Medline

3. Brinjikji W, Murad MH, Lanzino G, et al. Endovascular treatment of intracranial aneurysms with flow diverters: a meta-analysis. Stroke 2013;44:442-47 CrossRef Medline

4. Yu SC, Kwok CK, Cheng PW, et al. Intracranial aneurysms: midterm outcome of Pipeline embolization device-a prospective study in $\mathbf{1 4 3}$ patients with $\mathbf{1 7 8}$ aneurysms. Radiology 2012;265:893901 CrossRef Medline

5. Kallmes DF, Ding YH, Dai D, et al. A new endoluminal, flow-disrupting device for treatment of saccular aneurysms. Stroke 2007;38: 2346-52 CrossRef Medline

6. Kallmes DF, Ding YH, Dai D, et al. A second-generation, endoluminal, flow-disrupting device for treatment of saccular aneurysms. AJNR Am J Neuroradiol 2009;30:1153-58 CrossRef Medline

7. Velat GJ, Fargen KM, Lawson MF, et al. Delayed intraparenchymal hemorrhage following Pipeline embolization device treatment for a giant recanalized ophthalmic aneurysm. J Neurointerv Surg 2012; 4:e24 CrossRef Medline

8. Cruz JP, Chow M, O’Kelly C, et al. Delayed ipsilateral parenchymal hemorrhage following flow diversion for the treatment of anterior circulation aneurysms. AJNR Am J Neuroradiol 2012;33:603-08 CrossRef Medline

9. Turowski B, Macht S, Kulcsár Z, et al. Early fatal hemorrhage after endovascular cerebral aneurysm treatment with a flow diverter (SILK-stent): do we need to rethink our concepts? Neuroradiology 2011;53:37-41 CrossRef Medline

10. Hu YC, Deshmukh VR, Albuquerque FC, et al. Histopathological assessment of fatal ipsilateral intraparenchymal hemorrhages after the treatment of supraclinoid aneurysms with the Pipeline embolization device. J Neurosurg 2014;120:365-74 CrossRef Medline

11. Chalouhi N, Zanaty M, Jabbour PM, et al. Intracerebral hemorrhage after Pipeline embolization: management of antiplatelet agents and the case for point-of-care testing - case reports and review of literature. Clin Neurol Neurosurg 2014;124:21-24 CrossRef Medline

12. Fargen KM, Hoh BL. Ipsilateral cerebral hemorrhage following deployment of the Pipeline embolization device. J Neurosurg 2014;120: 363-64 CrossRef Medline

13. Delgado Almandoz JE, Crandall BM, Scholz JM, et al. Last-recorded P2Y12 reaction units value is strongly associated with thromboembolic and hemorrhagic complications occurring up to 6 months after treatment in patients with cerebral aneurysms treated with the Pipeline embolization device. AJNR Am J Neuroradiol 2014;35: 128-35 CrossRef Medline

14. Kallmes DF, Hanel R, Lopes D, et al. International retrospective study of the Pipeline embolization device: a multicenter aneurysm treatment study. AJNR Am J Neuroradiol 2015;36:108-15 CrossRef Medline

15. De Leon D, Swank G, Mirza MA. Radial artery sterile granulomatous reaction secondary to hydrophilic-coated sheath used for tran- 
sradial cardiac catheterization: a case series. Angiology 2012;63: 560-62 CrossRef Medline

16. Zellner C, Ports TA, Yeghiazarians Y, et al. Sterile radial artery granuloma after transradial procedures: a unique and avoidable complication. Catheter Cardiovasc Interv 2010;76:673-76 CrossRef Medline

17. Zellner C, Yeghiazarians Y, Ports TA, et al. Sterile radial artery granuloma after transradial cardiac catheterization. Cardiovasc Revasc Med 2011;12:187-89 CrossRef Medline

18. Ganesan S, Felo J, Saldana M, et al. Embolized crospovidone (poly[ $\mathrm{N}$-vinyl-2-pyrrolidone]) in the lungs of intravenous drug users. Mod Pathol 2003;16:286-92 CrossRef Medline

19. Delgado Almandoz JE, Crandall BM, Scholz JM, et al. Pre-procedure $\mathrm{P} 2 \mathrm{Y} 12$ reaction units value predicts perioperative thromboembolic and hemorrhagic complications in patients with cerebral aneurysms treated with the Pipeline embolization device. J Neurointerv Surg 2013;5(suppl 3):iii3-10 CrossRef Medline

20. Takigawa T, Suzuki K, Sugiura Y, et al. Thromboembolic events associated with single balloon-, double balloon-, and stent-assisted coil embolization of asymptomatic unruptured cerebral aneurysms: evaluation with diffusion-weighted MR imaging. Neuroradiology 2014;56:1079-86 CrossRef Medline

21. Hong Y, Wang YJ, Deng Z, et al. Stent-assisted coiling versus coiling in treatment of intracranial aneurysm: a systematic review and meta-analysis. PLoS One 2014;9:e82311 CrossRef Medline

22. McLaughlin N, McArthur DL, Martin NA. Use of stent-assisted coil embolization for the treatment of wide-necked aneurysms: a systematic review. Surg Neurol Int 2013;4:43 CrossRef Medline

23. Tomas C, Benaissa A, Herbreteau D, et al. Delayed ipsilateral parenchymal hemorrhage following treatment of intracranial aneurysms with flow diverter. Neuroradiology 2014;56:155-61 CrossRef Medline

24. Rodling-Wahlstrom M, Olivecrona M, Koskinen LO, et al. Subarachnoid haemorrhage induces an inflammatory response followed by a delayed persisting increase in asymmetric dimethylarginine. Scand J Clin Lab Invest 2012;72:484-89 CrossRef Medline

25. Chiu AH, Wenderoth J. Cerebral hyperperfusion after flow diversion of large intracranial aneurysms. J Neurointerv Surg 2013;5:e48 CrossRef Medline

26. Murakami H, Inaba M, Nakamura A, et al. Ipsilateral hyperperfusion after neck clipping of a giant internal carotid artery aneurysm: case report. J Neurosurg 2002;97:1233-36 CrossRef Medline

27. Tan LA, Keigher KM, Munich SA, et al. Thromboembolic complications with Pipeline embolization device placement: impact of procedure time, number of stents and pre-procedure $\mathrm{P} 2 \mathrm{Y} 12$ reaction unit (PRU) value. J Neurointerv Surg 2015;7:217-21 CrossRef Medline 